\title{
Educating Global Citizenship in a Changing World via After-school Music Program in Korea
}

\author{
Yoonil Auh ${ }^{1 \star}$, Mihee $\mathrm{Im}^{2}$, Chanmi Kim ${ }^{2}$, Sang-eun Hwang ${ }^{3}$
}

\author{
${ }^{1}$ Kyung Hee Cyber University, Seoul, SOUTH KOREA \\ ${ }^{2}$ Music for One Foundation, SOUTH KOREA \\ ${ }^{3}$ Hansei University, SOUTH KOREA \\ *Corresponding Author: yoonilauh@gmail.com
}

Citation: Auh, Y., Im, M., Kim, C., \& Hwang, S. (2021). Educating Global Citizenship in a Changing World via After-school Music Program in Korea. Pedagogical Research, 6(4), em0109. https://doi.org/10.29333/pr/11302

\section{ARTICLE INFO}

Received: 25 Jul. 2021

Accepted: 27 Sep. 2021

\section{ABSTRACT}

Purpose: Centered on the framework of global citizenship education (GCED), an after-school music program was developed for middle school students in Korea. The program aims to introduce multicultural topics to improve intercultural understanding and promote multicultural sensitivity for community relations development in response to rapid demographics changes in Korea. A total of 143 students have participated in the twenty-nineweek (29) pilot program. The program included orchestra and ensemble performances, learning ethnic songs and cultural backgrounds, and related educational activities.

Research method: Methodological triangulation was used to evaluate the significance of the program. Program surveys, formative and summative evaluations, and interviews were used as the assessment instruments to measure the program outcome.

Results: A music program based on the framework of GCED provided a good platform for gaining knowledge on teaching civic and multicultural education. The program displayed a measurable gain in students' positive attitudes towards community relations.

Keywords: music education, global citizenship education, intercultural understanding, multicultural curriculum

\section{INTRODUCTION}

Korea has undergone a major transformation since the Korean War. In the past seventy years, the advancing industrialization from agriculture to manufacturing, economic development, urbanization, demographic transformation, and changes in family life constitute the major features of the transformation. Due to the transformation of industry sectors, escalating numbers of migrant workers from abroad as well as intercultural marriages have been highly visible and reported. Today intercultural encounters happen in major cities as well as on rural farms in Korea-at work and in local schools. While multicultural populations bring new perspectives to society and communities, such as diversity, they also bring unique unforeseen challenges. Cultural issues arise from multiple layers of entities, where Morris and colleagues $(2015$, p. 632$)$ explain: "it comes from a loosely integrated system of ideas, practices, and social institutions that enable coordination of behavior in a population." Most people assume others should think, behave, and perceive the world around them as the same as they do (Pedersen 1965; Schneider 1973), but, this often leads to misunderstandings and even unintentional conflicts (Forgas \& O'Driscoll, 1984; Hong et al., 2003). Hinner (2017, p. 885) quotes "culture can be one of the causes for such misunderstandings and conflicts because culture influences to a large extent how individuals perceive the world around them, what meaning they attach to what they perceive, and how to respond to those perceptions." While culture has some influence on people's behaviors, culture does not explain how individuals manage conflict and how it influences the characteristics of individuals (Gunkel et al., 2016). These individual characteristics are based on how we are brought up and taught, where we come from, how we perceive the world around us, what peer and media messages we have internalized, how we perceive others, how we think others perceive us, and how we then interact and communicate with others (Adler et al., 2013; DeVito, 2015). Simply put, our characteristics are not shaped by isolated learning but through interacting and interrelating with others. Intercultural misunderstandings and conflicts are often witnessed not only in Korea but in all parts of the world. This most complex phenomenon has been the subject of much research. Each culture, like the perspectives of each religion, has its approach to interpreting the world, thereby identifying who they are and their relationships with the surroundings.

This paper discusses the design and development of an after-school intercultural intervention music program that aims to educate global citizens in a changing world. The program hopes to teach about the betterment of other people's lives and social well-being by learning to understand some of the current multicultural and global issues through musical activities. 
Table 1. Multicultural students in international married families and foreign families

\begin{tabular}{|c|c|c|c|}
\hline Year & Multicultural Students & Born in Korea & Foreign Born \\
\hline 2019 & 137,225 & 108,069 & 8,697 \\
\hline 2018 & 122,212 & 98263 & 8320 \\
\hline 2017 & 109,387 & 89314 & 7792 \\
\hline 2016 & 99,186 & 79134 & 7418 \\
\hline 2015 & 82,536 & 68099 & 6261 \\
\hline 2014 & 67,806 & 57498 & 5602 \\
\hline 2013 & 55,780 & 45814 & 4922 \\
\hline 2012 & 46,954 & 40040 & 4288 \\
\hline
\end{tabular}

Source: Korea Ministry of Education (2019)

\section{CURRENT STATUS}

Korea is experiencing a rapid decrease in the fertility rate while witnessing a growth in the number of migrant workers and intercultural marriages, creating a community renaissance (Seo, 2019). According to the statistics report by Korea Tourism Organization, prior to the COVID-19 global pandemic, nearly 1.467 million people passed through the customs and stayed 91 days or more (Statistics Korea, 2020). Demographics change due to increasing tourism, increased numbers of migrant workers, and intercultural marriages have brought cultural diversity creating a unique harmony, but also increased challenges to the comfort levels of community members. Given South Korea's very strong sense of national, ethnic, and racial pride, the increase in foreign migration over the decade is blemished by an escalating threat to the comfort zone, hostility, and an undercurrent of racial bias and attitudes (Shin et al., 2019).

Due to multilayer shifts in demographics, the changes are being reflected in schools. Based on the 2019 Trends of Multicultural Students by Year (Korea Ministry of Education, 2019), the number of multicultural students has increased each year; the number of attendants in school reached a record high in 2019 of 137,225 K-12 students, which this number had steadily increased since 2012 of 46,954 (Table 1).

According to Korea Educational Development Institute (KEDI 2019: 44):

"Multicultural students are considered children of international married families and foreign families. The children born in Korea refer to children born in Korea among children born to foreign spouses who are married to Koreans, and children born in Korea are children of international marriage families who were born abroad and entered Korea with their parents."

In 2019, due to Korea's low fertility rate, the total number of kindergarten, elementary, middle, and high school students at the national level decreased by $2.7 \%$ (down to 172,930) from the previous year. On the other hand, the proportion of multicultural students increased by $12.3 \%$ (an increase of 15,013 ). By school level the change was: for elementary school students, $3.8 \%(0.4 \%$ more than the previous year's 3.4\%, middle school students were $1.7 \%$ ( $0.3 \%$ more than the previous year's $1.4 \%)$, and multicultural high school students were $0.8 \%$ (an increase of $0.1 \%$ over the previous year (0.7\%) (Ministry of Education, 2019: 5). According to the $2019 \mathrm{KEDI}$ report, the regional expenditure of the multicultural student population indicates that this population does not reside in one part of the region, but is spread across the nation.

\section{OBJECTIVES OF THE STUDY}

Demographic changes are taking place in schools, and it is here that our concerns with the treatment of others different than ourselves, begin. Intercultural understanding overlaps with the ethics of learning to live together, which reflects on broader questions about citizenship, human rights, and the ethical treatment of others (Lynch et al., 2011). The purpose of this study is to develop an afternoon school music program that undertakes to promote intercultural understanding centered on the framework of Global Citizenship. The study expects to:

1. Determine whether the GCED curriculum can be developed using music at its core.

2. Determine whether music can be used to bring together the students' interests in multiculturalism and to increase their understanding of cultures beyond their own.

3. Determine whether a music program and related education activities can be designed to promote multicultural sensitivity.

The Korean government has responded by providing regional community-development programs such as Character Education (CE), Global Citizenship Education (GCED), Peace Education (PE), or Intercultural Understanding (IU) to promote positive community relationships in the hope of creating sustainable community lifestyles. These programs are typically offered in community centers and high schools and often integrated into existing subjects, such as social studies or geography, and taught by instructors who majored in the related fields, such as social studies and social services. However, promoting intercultural understanding to develop healthy community relationships through music activities has so far been limited or non-exist in Korea. Music or arts were rarely a part of teaching intercultural understanding and they were typically pitched as a part of the entertainment in school events such as a multicultural day or locally sponsored international festivals. However, music and its uses can be further explored beyond their appearances in local festive events. 
Music exists in every human society and has been fundamental to the nature of man (Garfias, 1983) and has functioned in the context of the personal and world view of each culture in each society. Music carries a set of unique codes and patterns, which are universally understood (Juslin, 2013; Whiteford et al., 2018). Music, therefore, can be a core feature of social celebrations, such as weddings, as a means of cultural expression and maintenance through the ceremony (Barton \& Riddle, 2021). According to research conducted by Mehr et al. (2019), they found that, across societies, music is associated with behaviors such as infant care, healing, dance, and love (among many others, like mourning, warfare, processions, and ritual), and they discovered that songs that share behavioral functions tend to have similar musical features:

"[...] music pervades social life in similar ways all around the world " (Mehr, et al., 2019:1). Music does appear to be tied to specific perceptual, cognitive, and affective faculties, including language (all societies put words to their songs), motor control (people in all societies dance), auditory analysis (all musical systems have signatures of tonality), and aesthetics (their melodies and rhythms are balanced between monotony and chaos)." (Mehr et al., 2019, p. 3).

Music therefore can be considered a viable communications mechanism that can be used to convey culture and history where it has no boundaries for integrating it in most subjects.

\section{PROGRAM DESIGN AND DEVELOPMENT}

\section{Global Citizenship Education (GCED)}

Global Citizenship Education (GCED) is a category of civic education endorsed by the United Nations' Sustainable Development Goals (SDGs) in which students are educated to actively participate in projects that address global issues of a social, political, economic, or environmental nature (UNAI, 2015). GCED aims to empower learners of all ages to assume active roles, both locally and globally, in building more peaceful, tolerant, inclusive, and secure societies (UNESCO, 2015). The core of GCED is to nurture the learners to have respect for all and therefore developing a sense of belonging to common humanity by becoming proactive contributors to a more peaceful and more inclusive and secure world. GCED helps young people develop the core competencies that allow them to actively engage with the world, and help make it a more just and sustainable place (UNAI, 2015).

\section{Curriculum Development}

The program was developed to improve intercultural understating as a part of the movement for community improvement education for middle school students. Therefore, the program centers on the value "ethics of care," "understanding others," and "improving community relations" through learning the cultures of others through music and its history. The uses of music should be open to multiple interpretations and applications. The framework of the after-school program was based on the following research questions:

1. Can music be an effective learning tool to introduce global citizenship?

2. Can music be an effective subject to educate students about a different culture, geography, and history?

3. Can music be a centerpiece for increasing the sense of belonging to common humanity through learning to share values and developing respect for differences and diversity?

4. Can music synthesize with civic education be a value to designing global citizenship education?

Music and Arts Enrichment Opportunities with Ethnic Songs and its Historical Background

Public schools offer music and arts enrichment opportunities through orchestra, chorus, or social-dance programs, however, these programs are limited to teaching technical skills to play the instruments or perform the required dance steps. The music curriculum in Korean middle school is mainly shaped by the music education methods from the West where the Western composers from the past-for example, Bach, Beethoven, Mozart, Vivaldi, John Philip Sousa-and popular movie theme songs are mainly introduced. In general, the music curriculum is comprised of limited songs representative of non-Western cultures. While there has been made advancement at the turn of the new millennia to include ethnic music in the curriculum (Hebert, 2000), the songs of cultures that are classified as a "nation in development" have all too often been omitted from the public school music textbooks or have been represented in such a way as to further negative attitudes among members and non-members of these cultures (Moore, 1974). Therefore, specific songs were selected for the program based on the breakdown by nationalities' presence in the community (Table 2 ) then selected songs were rearranged to be played in orchestras and ensembles. The breakdown by nationality in Korea is provided.

According to the 2020 Korea Population Census (Statistics Korea), 2,524,656 foreign residents reside in Korea. The babies born into multicultural families accounted for $5.5 \%$ of all newborns in South Korea, the highest percentage since the state statistics office began compiling the data in 2008 (The Korea Harold, 2019). The selected music for the program reflects the largest demographics of immigrants or visiting workers in Korea and they were: China, Vietnam, Thailand, and the United States. Few additional songs were included that represented the ethnicity of students in the school district, such as the Philippines, Cambodia, and Myanmar. Each country's history, national music, heritage sites, and traditional songs were included. In addition, traditional music listening sessions were included in the curriculum, for example, Bluegrass and Rock and Roll for the United States. Selected songs were orchestrated for the middle school level to be performed at the end of the program concerts.

As part of the program, all participants were required to learn to play a musical instrument-violin, flute, cello, or viola. The rationale for selecting these instruments is that participating schools are already equipped with the instruments and the music 
Table 2. The 2019 Korea population census

\begin{tabular}{|c|c|c|}
\hline Rank & Country & Population \\
\hline 1 & China & 1101782 \\
\hline 2 & Vietnam & 224,518 \\
\hline 3 & Thailand & 209,909 \\
\hline 4 & United States & 156,982 \\
\hline 5 & Japan & 86,196 \\
\hline 6 & Uzbekistan & 75,320 \\
\hline 7 & Philippines & 62,398 \\
\hline 8 & Russia & 61,427 \\
\hline 9 & Indonesia & 48,854 \\
\hline 10 & Mongolia & 48,185 \\
\hline 11 & Cambodia & 47,565 \\
\hline 12 & Nepal & 42,781 \\
\hline 13 & Taiwan & 42,767 \\
\hline 14 & Kazakhstan & 34,638 \\
\hline 15 & Myanmar & 29,294 \\
\hline 16 & Canada & 26,789 \\
\hline 17 & Sri Lanka & 25,064 \\
\hline 18 & Hong Kong & 20,018 \\
\hline 19 & Bangladesh & 18,340 \\
\hline 20 & Australia & 15,222 \\
\hline 21 & Malaysia & 14,790 \\
\hline 22 & Pakistan & 13,990 \\
\hline 23 & India & 12,929 \\
\hline 24 & Others & 104,898 \\
\hline TOTAL & & $2,524,656$ \\
\hline
\end{tabular}

Source: Korea Ministry of Education (2019)

teachers. The teaching of musical instruments was conducted via group pedagogy ( 3 or 4 ) where they all played the same instrument. The group pedagogy method was based on the Harmony Nation music education method (Hyundae, 2018). The rationale for selecting Harmony Nation (HN) music was: they are published by a widely recognized music publishing company in Korea; and it is the only music method whose education framework emphasizes peer-based and collaborative learning, introduces diverse music repertoire, and provides cultural information for each song in the book.

\section{The After-school Music Program: Global Cultural Citizenship Education}

The design of the after-school music program is about making connections with music and the diverse world. Therefore the program was named Global Cultural Citizenship Education (GCCE). It aimed to seek unrealized potential and opportunities for learning civic responsibilities and multicultural sensitivity by integrating traditional means of learning ethnic music and songs. The curriculum was developed based on Education for Global Citizenship a Guide for Schools (Oxfam, 2014) a focus on SDG Target 4.7 - "knowledge and skills needed to promote sustainable development and promotion of a culture of peace and non-violence, global citizenship, and appreciation of cultural diversity and culture's contribution to sustainable development" (UNESCO, 2018). Based on the Guide, the curriculum was to be constructed within the framework of (1) knowledge and understanding, (2) skills, and (3) values and attitudes for promoting global citizenship (GC). The GC is based on the following framework:

(1) Knowledge and understanding - the curriculum includes but is not limited to social justice and equity, diversity, globalization and interdependence, sustainable development, and peace and conflict (Oxfam, 2014).

(2) Skills - include critical thinking, ability to argue effectively, respect for people and things, co-operation, and conflict resolution (Oxfam, 2014).

(3) Values and attitudes- it includes a sense of identity and self-esteem, empathy and sense of common humanity, value and respect for diversity, concern for the environment and commitment to sustainable development, and belief that people can make a difference (Oxfam, 2014).

While there are myriad topics on global issues, using Oxfam's guide as a benchmark, the areas of learning were selected that were suitable for the community and applicable for the grade level. The selection was made through a series of meetings and discussions with the middle school teachers, music teachers, and civic education experts. Music educators were involved in order to determine the musical activities suitable for teaching global issues that were selected by the middle school teachers. The following learning activities were designed and developed for GC education using music:

(1) For knowledge and understanding of GC, the curriculum included a cultural history that coincided with selected music and songs. The learning activities include teaching the concept of globalization and interdependence, intercultural understanding and diversity, peace and conflict, and current global issues. Much of these topics are actively tied to music. For example, global K-pop stars, BTS, and Black Pink are actively promoting these topics through their music and words as well as appearing in talk shows related to global issues and peace. Music of peace and ecology protection by various contemporary composers was also included. 
(2) For learning skills of GC, the curriculum included playing ethnic and peace movement music through the orchestra practice, critical listening and discussion of ethnic music, and group projects related to global issues. The learning activities included short cultural history research and presentations and music performance in various community centers. These activities involve teamwork, small-size classes that generate critical thinking skills, musical instrument group lessons, and skills development for collaboration. These activities promoted students' ability to argue effectively, respect people and things, co-operate, and manage conflict.

(3) For learning values and attitudes of GC, community music performance activities were included as a part of participatory civic education. The activities include performing in community centers or schools in remote regions. These activities generate a sense of identity and self-esteem, empathy, value, and respect for diversity (Engin \& Sarsar, 2015).

The after-school music program is twenty-nine-week (29) where it consists of meeting three 45-minute workshops per week. The workshops include the following:

- Introduction to Global Citizenship Education (2 consecutive workshops)

- Music and Culture: Introduction to world music (3 consecutive workshops)

- World population and demographics changes (3 consecutive workshops)

- Sustainable Development Goals and the role of international organizations (United Nations, INGO, OECD, Internationally Human Rights Organizations) (3 consecutive workshops)

- The role of global citizens learning through music and culture (3 consecutive workshops)

- Orchestra (16 consecutive weeks)

- Group Lessons (24 consecutive weeks)

The goal of GCCE is to prepare students to learn about the betterment of other people's lives and social well-being by learning to understand some of the current intercultural and global issues through comprehensive music education. The program was based on a theory of education, 'learning by doing' (Dewey, 1938). It is a hands-on approach to learning, meaning students must interact with their environment to adapt and learn (Ord, 2012). The learn-by-doing theory is commonly applied because such progressive learning represents real-life problems to the children (DuFour, 2016). From this combined array of information, resources, and activities, GCCE was developed to promote students' specific understanding of intercultural and multicultural topics using music as the center learning piece. There were no tests or grades given at the end of the program. The program is designed on a team project-based and hands-on activity.

\section{SELECTION OF SCHOOLS, PARTICIPANTS, AND TEACHER PROFESSIONAL DEVELOPMENT PROGRAM}

Three schools were selected in Gyeonggi province Korea based on the commitment to the program by the school principal, school administrators. Students were selected on a voluntary basis within the selected schools. A total of 143 students, consists of $103(72 \%)$ female and $40(28 \%)$ male, participated in the GCCE program. A total of 25 parents volunteered to participate in the program. The parent's role was to attend to the children's needs during the program, such as students being on time for the afterschool program and for moral support. Regarding parental educational background, $98 \%$ of parents graduated from high school and $89 \%$ had college degrees. Through a rigorous selection process, Music for One Foundation provided eight music instructors and three global citizenship education experts to conduct and teach the program. In addition, curriculum design services, and administration of the program were provided. Participating schools were responsible for promoting the program in school and to parents and for providing the classrooms. A professional development program (PDP) for the GCCE participating teachers was developed and the workshops were conducted prior to the program. The aim of the PDP was to prepare the instructors for their assigned teaching activities as well as their administrative duties and communications protocols. The PDP consists of 3 hours per week for six weeks, a total of 18 hours. All instructors for the program were selected through applications, followed by interviews. All instructors were paid for their time for attending the PDP as well as for teaching the GCCE program. The PDP had a significant impact on maintaining the quality of the GCCE as well as the administrative flow of the program throughout 29 weeks.

\section{RESEARCH METHOD}

Methodological triangulation was used for the study. Triangulation is the use of multiple sources of data or information to validate the study. Triangulation is used to ensure validity, improve the accuracy of judgment, reduce bias, and inspire confidence in results. The study included three sources of data: (1) pre and post students' knowledge evaluation surveys, (2) formative and summative evaluations, and (3) program satisfaction surveys and semi-structured interviews. Semi-structured interviews are commonly used and included in qualitative research and it is an effective tool in interpretive research because they help the researcher gain in-depth data of participants' perspectives and make sense of their lived stories and experiences as told by them (Balushi, 2018). Figure 1 displays the methodological triangulation process.

The study was designed to ensure that all participants involved in the program were given a voice and that all findings are grounded in the learning experiences of participants. The study also focused on gathering information through providing an explicit rendering of the student knowledge and skills gained from the program in three areas-knowledge of global issues and 


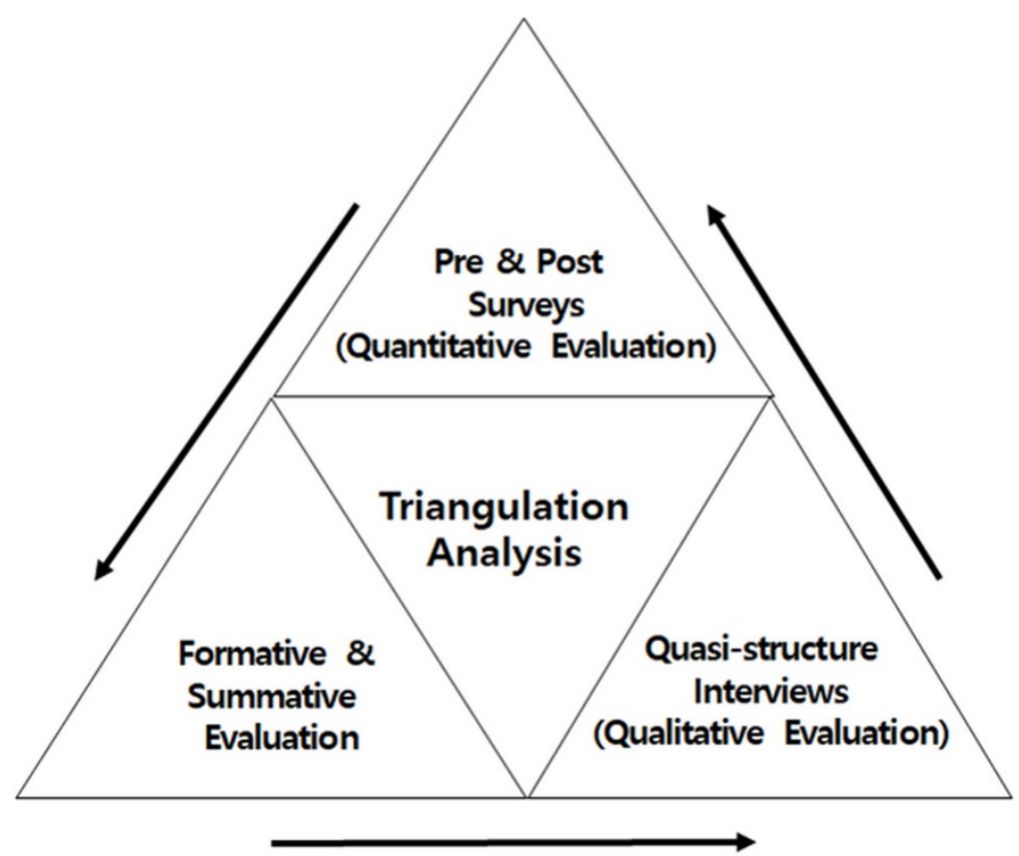

Figure 1. The process of triangulation used to evaluate the effectiveness of the GCCE program

cultural diversity, musical instrument playing skills, perceived attitude changes towards promoting community relationships, and interests for the future community services participation.

As the first source of data, pre and post students' knowledge evaluation surveys was conducted to gather participants' knowledge, skills, values, and attitudes related to geography, global issues, music theory, instrument playing skill, and civic responsibility. Pre-assessment aims to monitor student learning during the GCCE program and provide ongoing feedback that instructors can use for students to improve student learning. Pre-assessment assists students to see their strengths and weaknesses so they can work on areas that need to be improved. For the teachers, such information helps them recognize where students are struggling, so they can act immediately to address the problems. At the end of the program, post students knowledge evaluation survey was conducted to evaluate students' knowledge gain and learning experiences.

The second source of data came from the formative and summative evaluations. A formative evaluation was used in the development of the program to inform the providers and stakeholders about the trends in results, whether the goals of the program are likely to be fulfilled and to identify the barriers and facilitators of implementation (Janus \& Brinkman, 2010). Results of the formative evaluation are then incorporated into the program with the necessary adjustments made to improve program implementation (Janus \& Brinkman, 2010). For example, do instructors need to re-exam the sequence of the learning topics? Do instructors need to explain the concepts differently using examples and case studies? If so, what should be considered for selecting examples and case studies? Formative evaluation is used to provide both the students and instructor with a gauge of where their level of understanding is at the current moment and enable the instructor to adjust accordingly to meet the emerging needs of the class (UC Berkeley Center for Teaching \& Learning, 2021). The summative evaluation was used to evaluate student's learning at the end of the GCCE program by comparing it against the Global Citizenship education standard and the benchmark that was developed during the curriculum development.

Finally, program satisfaction surveys and semi-structured interviews were conducted. The program satisfaction surveys were conducted for the parents, students, and teachers. The framework of the program satisfaction survey was adopted and modified from 'Measuring student satisfaction from the Student Outcomes Survey' by the National Centre for Vocational Education Research of Australia (Fieger, 2012). All information was gathered and used to validate the efficacy of the GCCE program.

\section{LEARNING OUTCOMES}

The student survey response rate was $92 \%$ or 131 responses from 143 participants; from parents, it was $78 \%$ or 19 responses from 25. The students were informed about the purpose of the surveys via an information sheet delivered to participating schools. The parents and students acknowledged that their participation in the survey is voluntary. Pre and post students' knowledge evaluation surveys were used to measure and compare the knowledge, skills, values, and attitude gained from the program; and the areas of interest development after completing the program. The surveys are structured in three parts (sections): the first part consists of participants' basic knowledge and understanding in regards to geography, global issues, music theory, instrument playing skills, civic responsibility. The second part consists of participants' areas of academic interests that include (1) musical interest; (2) aesthetic/arts interest; (3) interpersonal/self-reflective interest; (4) nature/environmental interest; (5) logic and mathematical interest; (6) linguistic interest; (7) interpersonal/social and community interest; and (8) kinesthetic interest. The division of the eight-part intelligence framework was adapted from Gardner's Theory of Multiple Intelligences (Gardner, 2000). The academic Interest survey is one way to understand the SWOT profile of the students to map their possible interests, skills. 
10

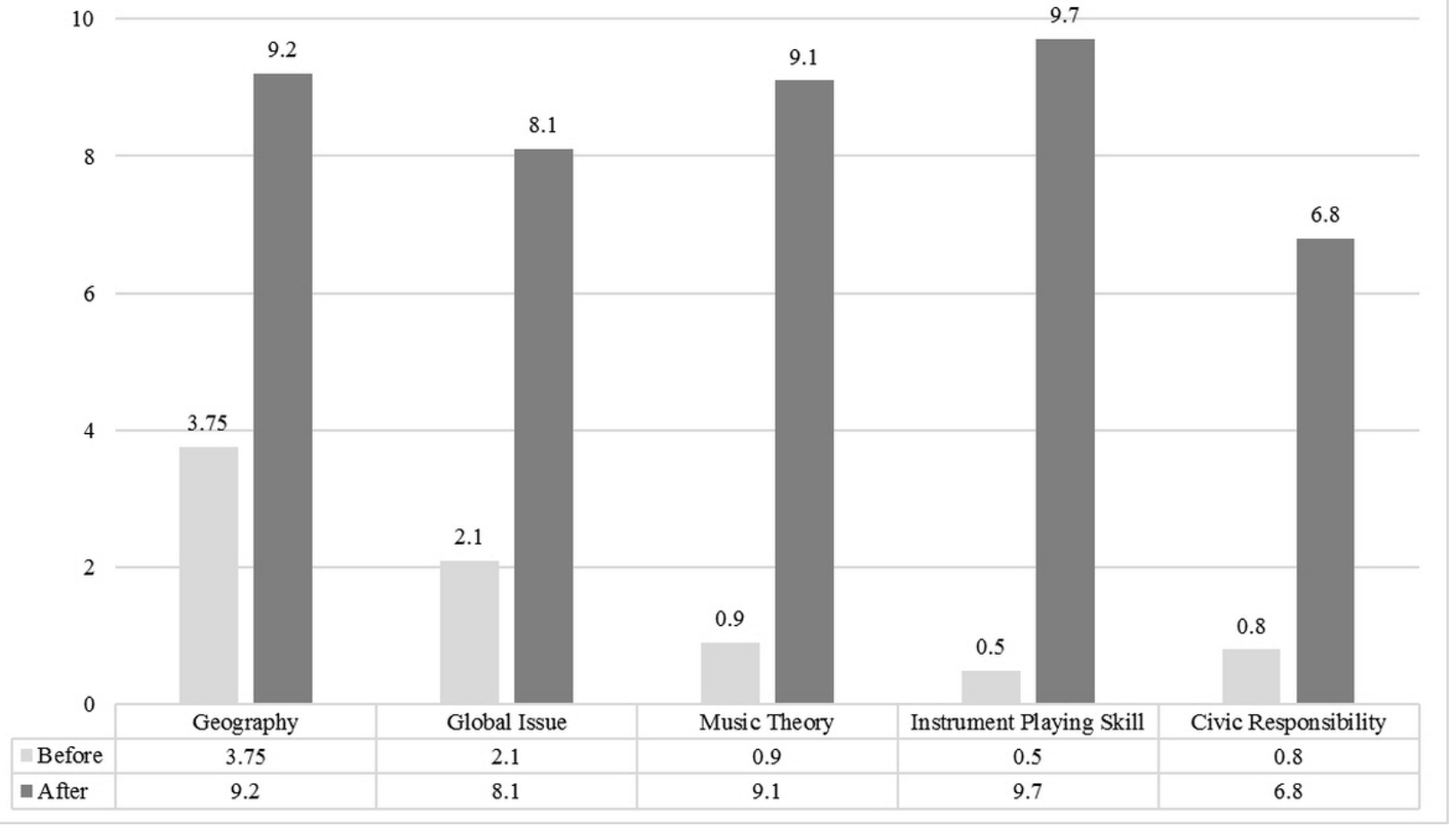

Figure 2. Participants' average knowledge gained by subject

Therefore, the survey was conducted to survey students' extracurricular growth through understanding students' multidimensional profiles therefore, hope to gain areas of motivation/interest of the students. The third part consists of a program satisfaction survey for students, parents, and staff.

\section{Pre and Post Students' Knowledge Evaluation Surveys}

The survey consists of 10 questions for each area of study - a total of 50 questions - and students were to select the correct answers for each question. Figure 2 displays the result of pre- and post-comparison of students' knowledge gained from the program. The graph in Figure 2 indicates the average number of correct answers for the participants.

On a scale of 0 to 10 , the average of correct answers scored in the geography section was 3.75 prior to attending the program and at the completion of the program, the average score escalated to 9.2. The familiarity of global issues was 2.1 prior to attending the program and the average score escalated to 8.1. Knowledge of music theory changed from 0.9 to 9.1. Musical instrument playing knowledge and skills increased from 0.5 to 9.7. The significant increase in musical instrument playing knowledge was due to the fact that all students were novice players at the beginning of the program and were required to learn a musical instrument as a part of the GCCE program.

\section{Areas of Academic Interest Development}

The survey consists of 10 questions for each area of academic interest- a total of 80 questions. For each survey question, a Likert-type scale was used from 1' to 5', and it was marked with the ones most appropriate to the respondents' thoughts from "very disagreeable" (1) to "very agreeable" (5). Figure 3 displays the results of pre-and post-comparison of students' academic interest development. Prior to the program, student's interest in the eight areas was distributed on a scale of 0 to 10 , the average interest being 3.625. The interest after the program was distributed on a scale of 0 to 10 , the average increased to 6.625 . In particular, students' interest in music increased from 4 to 7 . Some areas show a relatively larger increase than others. In all the pre-and post-measured results, the area with the greatest interest of students in the field related to physical activity, which was related to activities related to community services through teamwork.

\section{Program Satisfaction Survey for Students}

Using the framework of the 'Student Outcomes Survey' by the National Centre for Vocational Education Research of Australia (Fieger, 2012), the program satisfaction survey was designed for the students, parents, and staff. The survey is structured in two parts: (1) Quantitative, which consists of 12 questions with three responds to select from, and (2) open-ended qualitative questions to reflect their learning experience from the program. This learning satisfaction survey was conducted to confirm the perceived change of values and attitudes of students participating in the program. The part 1 survey consists of 12 questions; each student replies 'yes', 'no', or 'not sure'. The survey response rate was $92 \%$ (131 out of 143) and the results showed that students who are positively aware of change show more overwhelming responses than students who are unsure of change or who are negatively 


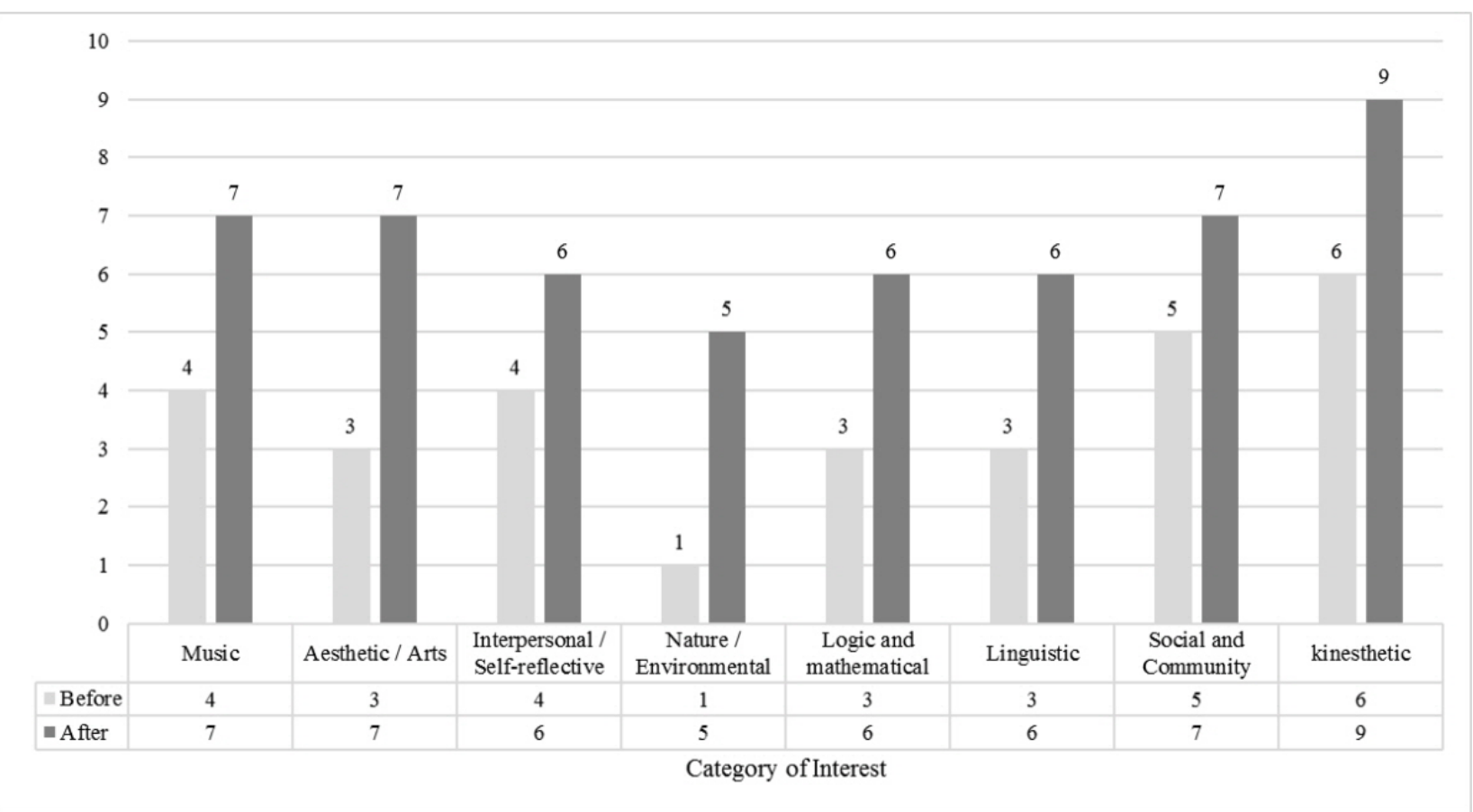

Figure 3. Pre and post-test for participants' areas of academic interests

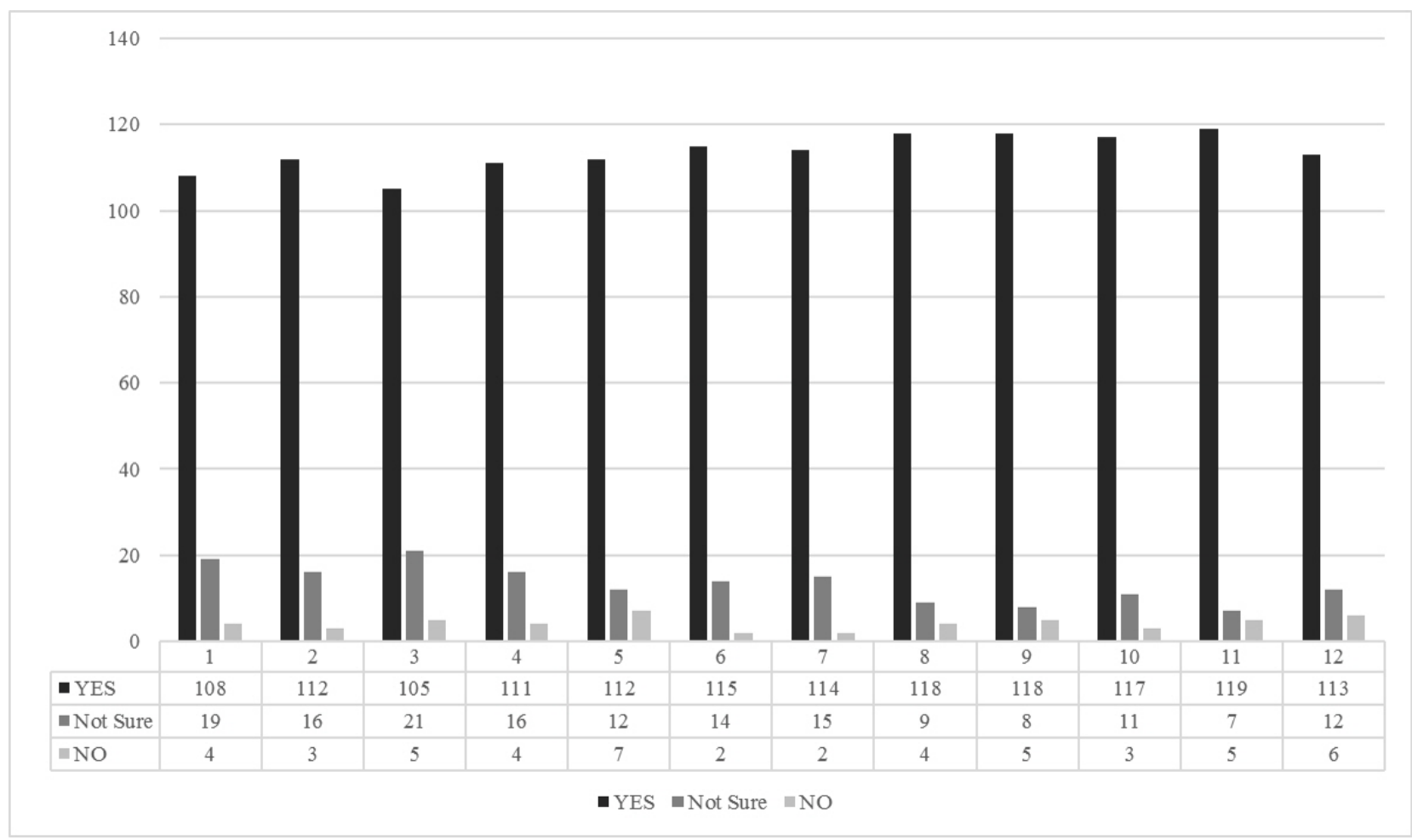

Figure 4. Student program satisfaction survey

aware of the change. Of 131, 111 (86\%) participants replied with positive reactions towards the program; 13 (10\%) participants replied 'not sure' if the program had an impact on their values and attitudes towards multicultural issues; 5 (3\%) replied, 'No impact'; and 2 participants replied no answers. Figure 4 displays the result of each question on the survey.

Below are selected open-ended comments expressed in the survey from $85 \%$ of the participants who had a positive impact:

- "I learned that we can work together to make a better world."

- "I feel we are all living in a new world after completing the class."

- "I learned that we should respect everyone in the world for who they are."

- "I gained the confidence to start a conversation with people of different ethnic backgrounds in my community."

- "I am open to people with different ethnic backgrounds more now than before." 
- "I should learn to accept people with different lifestyles."

- "I feel their culture is just as important than mine."

- "Environmental issues are a global problem and my problem."

- "I felt that I should participate in environmental protection each day simply by practicing what I learned, such as saving water, electricity, and other resources."

- "I learned about various world issues. That was an eye-opening experiences for me."

- "I want to volunteer to help to improve my community. I think its important to all work towards common goals."

- "I want to participate in activities related to the environment."

- "I am willing to donate my time to those who need help."

- "I can now understand the importance of a relationship with people and why I should be a part of solving the issues and learn to help each other."

- "They [people of other cultures] have feelings just like I have."

At this point, we can safely conclude that students are likely to participate in activities such as community service with civic consciousness. Nonetheless, it is conceivable that the programs as designed have influenced participants' views of the world and the importance of intercultural understanding through musical learning activities.

\section{Program Satisfaction Survey for Parents}

The program satisfaction survey for parents was conducted to collect feedback on the program and suggestions for improvement:

- $78 \%$ or 19 responded that the program promoted their interests in both music and global citizenship education and the majority felt that the use of music seemed a natural approach for improving conflict management and community relations.

- $8 \%$ or 2 responded that they were not sure, but this program was in fact more interesting than learning the topics only in a class by memorizing facts and events that are related to global issues.

- $14 \%$ or 4 responded that they didn't know how much the program will have a long-term impact on students.

- $84 \%$ or 21 responded the program would help their children's schoolwork

- $14 \%$ or 4 responded they were not sure if such activities would help, but did say it would not hurt.

The parents and guardians of participants all were interested in participating in the program again if it was offered the following year. For the record, there were no negative responses from parents towards the operations management as well as the content of the program. The parents' survey indicated that they desired similar programs in the future and if this program was to be offered again, they prefer more musical performance opportunities for the students and seminars on the topics of global issues for the parents. The parents' survey provided ample opportunity for parents to suggest ways to improve the program. They hope the program to be offered frequently rather than once a year or on a trial basis and they also hope to have at least two orchestra performances during the duration of the program.

\section{Interviews with Teachers and Participating School Staff}

Semi-structured interviews were conducted to gain in-depth perspectives from the instructors and school staff. The interview was approximately 20 minutes each to gather their perspectives and make sense of their lived stories and experiences as told by them. A total of 21 interviews were conducted, and below, the key contributing factors have been extracted from the interviews.

Interview 1: "For many months, parents had sought affordable music programs to be offered in school, specifically learning musical instruments. This program offered what we needed. Also, not only students learned the skills of playing the instrument, but I was pleased to see students were learning to work together, especially peer teaching activities."

Interview 2: "We were looking for a program that extends throughout school vacation. This program offered such an opportunity. Furthermore, the program motivates students to participate in civic engagement, not as a demonstrator of a specific civic movement but as a community-relations development activity, such as visiting children's hospitals to offer public concerts. I think that was the true value to this program."

Interview 3: "The program was innovative-I never thought one can learn music while learning another subject. It was well designed and I only hope this type of program is offered to more schools with the students of diverse populations."

Interview 4: "The program offered two important topics we needed-music performance education and global citizenship education. We considered this infused model the future of teaching topics related to civic education-culture infused with civic education."

Interview 5: "A typical education related to global citizenship, based on our experience, was perceived as incomplete and inadequate. Therefore, we felt that there are urgent need to redesign the GCED. However, we see this program model being highly unique-teaching music while learning global citizenship. This is a breath of fresh ideas. And I can see most students enjoying learning two areas at the same time." 
The responses from the interviews display overall satisfaction about learning two subjects in one program-musical instrumental playing and GCED. On a separate note, one of the parents revealed an open-ended question in the program satisfaction survey that at the beginning of the program she felt that learning a musical instrument would be a waste of time in the era of the fourth industrial revolution. Instead, spending more time studying core school subjects would have been a better choice. Another staff expressed similar concerns for adjoining two subjects into one and didn't see how music can be used to teach global citizenship. However, both the parents and staff had observed the program and as they expressed their sincere value of learning in teams, peer teaching, and learning by doing-that is, learned knowledge being applied to building community relations. This changed their perception and preconceived notion about the value of music as well as infusing music and global issues for teaching civic education. The participants all agreed that integrating music to learn cultural knowledge and promote community relations was an innovative approach to draw learner's attention to learning and not memorizing facts. The staff and parents were convinced that this type of learning opportunity is rare in schools in Korea and they hope to see more types of programs infused with innovative learning activities.

\section{DISCUSSION AND RECOMMENDATION FOR FUTURE RESEARCH}

One of the critical elements of this program model was that the students gained concert performance experience through playing at community centers and giving a final concert at the end of the program, which was held in one of the recognized concert halls in Seoul, Yongsan Arts Hall. The participants also agreed that the program is to be offered year-round instead of only half a year, and it should include the other instruments, such as clarinet, French horn, trumpet, and percussion. In light of the results of the study, several recommendations can be made. First, the results of the study revealed that professional development for the teachers is a critical element for the success of the program. Professional development includes teaching strategy and classroom management techniques for the afterschool program, topics of global citizenship, and multicultural community issues and case studies. Second, teachers' competencies in global citizenship (GC) are essential. While GC topics are covered in professional development workshops, participating teachers should be required to have basic knowledge of GC. Such can be accomplished in a number of ways that -additional global citizenship training program for teacher candidates be provided or required certification from a GCED approved educational institution. Third, the involvement of parents is just as important for the success of the program. Fourth, participating schools should carry out continuous evaluations of the GCCE program participants' growth and maintain communications with the GCCE program developers for the future development of the program. Based on the results of this study, comparative studies should be conducted between the GCCE curriculum and similar curricula that integrate music with civic education that is not centrally focused on global citizenship. Furthermore, comparative studies should be conducted on the effectiveness of the program with and without the application of performing arts subjects to determine the differences between the two programs for participants' achievements, values, and skills.

\section{CONCLUSION}

This study reports the outcome of an after-school music program targeted to middle school children for improving multicultural sensitivity for community relations development using the framework of global citizenship. The GCCE program was developed to educate middle school-aged students to learn about the betterment of other people's lives and social well-being by learning to understand some of the current intercultural and global issues through musical activities. The learning activities are centered on global issues as well as addressing multicultural-sensitive issues by "ethics of care" and "understanding others" therefore improving community relations. The study examined the possibility of infusing two programs, music and global citizenship for middle schools. Through formative and summative assessment, the research identified: (1) music can be used to bring together middle school students' interests in the global issues that are focused on multiculturalism; (2) an orchestra program can be designed to promote multicultural sensitivity; (3) music can be used to promote cultural values and intercultural understanding; and (4) global citizenship education curriculum can be developed with music education as a core of the study. Overall, the program provided a good platform for gaining knowledge on teaching civic education using music.

The GCCE program was funded by the City of Seoul Public-Private Partnership (PPP) Division and the program was developed in support of the Music for One Foundation (INGO) in Seoul, Korea. The program was designed for children to learn about understanding the core values of non-discrimination, respect for diversity, and solidarity for humanity while learning cultural history, ethnic music, and musical instrument playing skills. Most importantly, the program offered an opportunity for children to gain social skills, teamwork skills, and understand cultures beyond their own through musical activities. Such learning opportunities are rare in Korean schools. The findings of this research can be broadly applied to the study of integrating music with other core curriculum subjects such as creative writing and world studies.

Author contributions: All authors have sufficiently contributed to the study, and agreed with the results and conclusions.

Funding: This evaluation research received no specific grant from any funding agency in the public, commercial, or not-for-profit sectors.

Declaration of interest: No conflict of interest is declared by authors.

\section{REFERENCES}

Adler, R. B., Rodman, G., \& du Pré, A. (2013). Understanding human communication (12th ed.). Oxford University Press. 
Balushi, K. A. (2018). The Use of Online Semi-Structured Interviews in Interpretive Research. International Journal of Science and Research, 7(4), 726-732. https://doi.org/10.21275/ART20181393

Barton, G., \& Riddle, S. (2021). Culturally responsive and meaningful music education: Multimodality, meaning-making, and communication in diverse learning contexts. Research Studies in Music Education. https://doi.org/10.1177/1321103X211009323

DeVito, J. A. (2015). The interpersonal communication Book (14th ed.). Pearson.

Dewey, J. (1938). Experience and education. Macmillan.

DuFour, R., DuFour, R., Eaker, R., Many, T. W., \& Mattos, M. (2016). Learning by doing: A handbook for professional learning communities at work (3rd ed.). Solution Tree.

Engin, G., \& Sarsar, F. (2015). Investigation of primary school teacher candidates' global citizenship levels. Journal of Human Sciences, 12(1), 150-161. https://doi.org/10.14687/ijhs.v12i1.3159

Fieger, P. (2012). Measuring student satisfaction from the student outcomes survey. National Centre for Vocational Education Research (NCVER), Adelaide Australia. https://files.eric.ed.gov/fulltext/ED532394.pdf

Forgas, J. P., \& O'Driscoll, M. (1984). Cross-cultural and demographic differences in the perception of nations. Journal of CrossCultural Psychology, 15(2), 199-222. https://doi.org/10.1177/0022002184015002007

Gardner, H. (2000). Intelligence reframed: Multiple intelligences for the 21st century. Basic Books.

Garfias, R. (1983). Music in the United States: Community of cultures. Music Educators Journal, 69(9), 30-31. https://doi.org/10.2307/3396262

Gunkel, M., Schlaegel, C., \& Taras, V. (2016). Cultural values, emotional intelligence, and conflict handling styles: A global study, Journal of World Business, 51(4), 568-585. https://doi.org/10.1016/j.jwb.2016.02.001

Hebert, D. G. (2000). Tradition and modernity in South Korean music education: A critical analysis. Music Education, 27(2), 95-108. https://doi.org/10.1080/14613800050004468

Hinner, M. (2017). Intercultural misunderstandings: Causes and solutions. Russian Journal of Linguistics, 21(4), 885-909. https://doi.org/10.22363/2312-9182-2017-21-4-885-909

Hong, Y.-Y., Benet-Martinez, V., Chiu, C.-Y., \& Morris, M. W. (2003). Boundaries of cultural influence: Construct activation as a mechanism for cultural differences in social perception. Journal of Cross-Cultural Psychology, 34(4), $453-464$. https://doi.org/10.1177/0022022103034004005

Hyundai Music. (2018). Harmony Nation Music Education. Hyndai Music Publisher.

Janus, M., \& Brinkman, S. (2010). Evaluating early childhood education and care programs. In P. Perterson, E. Baker, \& B. McGaw (Eds.). International encyclopedia of education (3rd ed). Elsevier. https://doi.org/10.1016/B978-0-08-044894-7.01197-0

Juslin P. N. (2013). What does music express? Basic emotions and beyond. Frontiers in Psychology, $4,596$. https://doi.org/10.3389/fpsyg.2013.00596

KEDI- Korea Education Development Institute (2019). Educational statistics analysis data collection-Elementary and secondary education statistics SM 2019-05. KEDI of Korea. https://www.kedi.re.kr/khome/main/webhome/Home.do

Korea Ministry of Education (2019). Report of basic education statistics. Korea Ministry of Education. https://www.moe.go.kr/boardCnts

Lynch, P, Molz, J.G., McIntosh, A., Lugosi, P., \& Lashley C. (2011) Theorising hospitality. Hospitality \& Society, 1(1), 3-24. https://doi.org/10.1386/hosp.1.1.3_2

Mehr, S. A., Singh, M., Knox, D., Ketter, D. M., Pickens-Jones, D., Atwood, S. Lucas, C., Jacoby, N., Egner, A. A., Hopkins, E. J., Howard, R. M., Hartshorne, J. K., Jennings, M. V., Simson, J., Bainbridge, C. M., Pinker, S., O’Donnell, T. J., Krasnow, M. M., \& Glowacki, L. (2019). Universality and diversity in human song. Science, 366, eaax0868. https://doi.org/10.1126/science.aax0868

Moore, M. C. (1977). Multicultural music education: An analysis of Afro-American and native American folk songs in selected elementary music textbooks of the periods 1928-1955 and 1965-1975 (Doctoral dissertation). University of Michigan. ProQuest Dissertations and Thesis (302817880).

Morris, M. W., Chiu, C.-Y., \& Liu, Z. (2015). Polycultural Psychology. Annual Review of Psychology, 66(1), 631-659. https://doi.org/10.1146/annurev-psych-010814-015001

Ord, J. (2012). John Dewey and experiential learning: Developing the theory of youth work. Youth \& Policy, (108), 55-72.

Oxfam (2014). Education for global citizenship: A guide for schools. Oxfam, New Zealand.

Pedersen, D. M. (1965). The measurement of individual differences in perceived personality-trait relationships and their relation to certain determinants. The Journal of Social Psychology, 65, 233-258. https://doi.org/10.1080/00224545.1965.9919603

Schneider, D. J. (1973). Implicit personality theory: A review. Psychological Review, 79(5), $294-309$. https://doi.org/10.1037/h0034496

Seo, S. H. (2019). Low fertility trend in the Republic of Korea and the problems of its family and demographic policy implementation, Population and Economics, 3(2), 29-35. https://doi.org/10.3897/popecon.3.e37938

Shin, G. W., Choi, J. N., \& Moon, R. (2019). Korea's migrants: From homogeneity to diversity. Asian Survey, 59(4), 595-606. https://doi.org/10.1525/as.2019.59.4.595

Statistics Korea. (2020). Korean statistical information service. https://kosis.kr/eng/ 
The Korea Harold. (2019). Multicultural children. The Korea Harold, 12 November.

UC Berkeley. (2021). Formative evaluation. Center for Teaching \& Learning UC Berkeley. https://teaching.berkeley.edu/formativeevaluations

UNAI. (2015). Global citizenship education. United Nation Academic Impact. https://academicimpact.un.org/content/globalcitizenship-education

UNESCO. (2015). Global citizenship education. https://en.unesco.org/themes/gced

UNESCO. (2018). Schools in action: Global citizens for sustainable development. http://unesdoc.unesco.org/images/0024/002468/246888e.pdf

Whiteford, K. L., Schloss, K. B., Helwig, N. E., \& Palmer, S. E. (2018). Color, music, and emotion: Bach to the blues. i-Perception, 9(6), 1-27. https://doi.org/10.1177/2041669518808535 